\title{
"Aqui a gente planta em família": notas sobre a relação entre família e a lavoura de soja em assentamentos rurais do meio norte de Mato Grosso
}

Cristiano Desconsi ${ }^{1}$

Universidade Federal do Rio de Janeiro

Resumo: Este artigo tem como objetivo refletir sobre a relação entre família e exploração agrícola em assentamentos do meio norte do Mato Grosso. A reflexão baseia-se em dados etnográficos obtidos em assentamentos rurais entre 2008 e 2014 cujas terras estão, atualmente, totalmente ocupadas por lavouras de soja, não se diferindo, do ponto de vista da ocupação física do espaço, das grandes explorações agrícolas. Inspirando-se na noção de "rede", descreve-se um caso concreto a fim de demonstrar como os assentados ativam os familiares e, por vezes, os vizinhos para plantar soja e, por meio destes, mobilizam (ou tentam mobilizar) os recursos necessários para tal, produzindo e reproduzindo obrigações entre si. Por essa via, tanto se definem aproximações e distanciamentos entre membros "da família", bem como se constituem composições de áreas para implantar lavouras, transcendendo os limites do lote individual, além de estabelecer, manter ou alterar hierarquias sociais entre os envolvidos.

Palavras-chave: família, redes, soja, assentamentos rurais. 


\title{
"Here we plant in the family": notes on the relationship between family and soybean farming in rural settlements in the north of Mato Grosso
}

\begin{abstract}
This paper aims to reflect on the relation between family and agricultural exploitation in settlements in the mid-north of the Brazilian state of Mato Grosso. The reflection is based on ethnographic data obtained in rural settlements between 2008 and 2014 whose land is currently fully occupied by soybean crops, hence not differing, from the standpoint of physical occupation of space, from large agricultural enterprises. Inspired on the notion of "networking," a real-life case is described in order to demonstrate how settlers activate family members and, at times, their neighbors to plant soybean, and through those they mobilize (or attempt to do so) the resources required to that end, producing and reproducing obligations among themselves. Through this pathway, both approximation and distancing among members "of the family" are defined, as well as areas are composed to implement crops, transcending the limits of the individual plot, besides establishing, maintaining, or changing social hierarchies among those involved.
\end{abstract}

Keywords: family, networks, soybean, rural settlements.

\section{"Aquí nosotros plantamos en familia": notas sobre la relación entre la familia y el cultivo de soja en asentamientos rurales del medio norte de Mato Grosso}

\begin{abstract}
Resúmen: Este artículo tiene como objetivo reflexionar sobre la relación entre familia y explotación agrícola en asentamientos del medio norte de Mato Grosso. La reflexión se basa en datos etnográficos de los asentamientos rurales entre 2008 y 2014 cuya tierra actualmente está totalmente ocupada por cultivos de soya, que no se aparta desde el punto de vista de la ocupación física del espacio, las grandes explotaciones. Inspirado por el concepto de "red", describe un caso con el fin de demostrar cómo los campesinos permiten a los miembros de la familia $\mathrm{y}$, a veces los vecinos para plantar soya y, a través de ellos, movilizar (o tratar de movilizar los recursos) necesarios para ello, produciendo y reproduciendo obligaciones entre sí. De esta manera, ambos se definen las similitudes y diferencias entre los miembros de la "familia" y constituyen áreas de composiciones para desplegar los cultivos, más allá de los límites del lote individual, y para establecer, mantener o cambiar las jerarquías sociales entre las partes interesadas.
\end{abstract}

Palabras clave: familia, redes, soya, asentamientos rurales. 


\section{Uma área de expansão agrícola no meio norte mato-grossense}

$\mathrm{O}$

Brasil alcançou, nos últimos 10 anos, a segunda posição no ranking mundial na produção de soja. Isso ocorreu não só devido ao aumento da produtividade, mas também pela expansão das lavouras mecanizadas sobre novas áreas do Cerrado brasileiro incentivadas por inúmeras políticas de Estado (HEREDIA et. al., 2010; WESZ Jr., 2014). O meio norte do Mato Grosso é uma das áreas que contribuiu muito para alcançar essa posição, especialmente após a década de 1990, quando viveu o grande boom de expansão das lavouras de soja e milho (DESCONSI, 2011; ALMEIDA, 2013). Conforme expunham vários estudos, e não é difícil confirmar em campo, a "lavoura" é desenvolvida predominantemente em grandes explorações agrícolas (FERNANDEZ, 2007). Todavia, chama atenção a existência de inúmeros projetos de assentamentos de Reforma Agrária criados a partir de meados da década de $1990^{2}$, sobre os quais parece haver poucos estudos qualitativos, diante do destaque dado pelos pesquisadores e imprensa às grandes explorações agrícolas. Compreender de forma qualitativa as relações sociais que se construíram nesses assentamentos rurais, de forma particular, como se dá o envolvimento dos assentados ${ }^{3}$ com a produção de soja, foi o que nos motivou a realizar trabalho de campo em 2013 e 2014, do qual extraímos o material para essa reflexão ${ }^{4}$.

Os assentamentos do meio norte do Mato Grosso foram criados, em sua maioria, entre 1995-2004, sobre as "chapadas" 5 mais afastadas dos povoamentos e dos principais eixos rodoviários - como a BR-163 - existentes nessa época. O Instituto Nacional de Colonização e Reforma Agrária (Incra) promoveu a desapropriação de imóveis cujos proprietários, em sua maioria, mantinham suas terras como reserva de valor em áreas de baixa densidade demográfica ${ }^{6}$. Nesse período, estavam em andamento inúmeros conflitos fundiários nas áreas mais ao sul do estado (MORENO, 2007), onde também se situavam a maior parte dos acampamentos e ocupações de terra. Tais acampamentos eram constituídos de

\footnotetext{
${ }^{2}$ Segundo dados do INCRA, entre 1992 e 2003, foram criados 38 projetos, com 8.080 parcelas, totalizando 554 mil hectares na abrangência de municípios do meio norte do Mato Grosso (considerando 14 municípios).

3 Assentado é o termo utilizado para designar aqueles agentes que integram um projeto de assentamento de reforma agrária pelo Incra. É com esse significado que essa categoria aparece neste texto. Evidentemente, em situações específicas, essa categoria ganha sentidos políticos, sobretudo, quando posta em oposição às fazendas ou aos produtores. Porém esses sentidos não são examinados nos limites deste artigo.

${ }_{4}^{4}$ A reflexão desse artigo, integra a pesquisa de tese vinculada ao Programa de Pós-graduação em Sociologia e Antropologia da Universidade Federal do Rio de Janeiro (PPGSA/UFRJ), intitulada "O controle da lavoura: a construção de relações sociais e a produção de soja em assentamentos rurais do meio norte de Mato Grosso (Brasil). A definição dessa área do estudo, possuí relação com investimentos em pesquisa anteriores quando o autor participou do projeto "Sociedade e Economia do Agronegócio: um estudo exploratório", sendo, portanto, um desdobramento desta. Para mais sobre os resultados desse projeto ver http://campohoje.net.br/

${ }^{5}$ Denominam-se como "chapadas" as terras localizadas numa extensa faixa central que atravessa o estado do Mato Grosso de leste a oeste. Caracterizam-se por serem áreas planas ou levemente onduladas, onde predominava a vegetação típica do Cerrado e pelos solos que apresentam baixa fertilidade natural. A partir dos anos 1980, passaram a ser muito valorizadas para a implantação da agricultura mecanizada de produtos como arroz, soja, milho e algodão. Os assentamentos que nos referimos neste trabalho localizam-se em terras com essas características.

${ }^{6}$ Os processos de expulsão de populações nativas que habitavam essas terras parecem ter ocorrido com intensidade nas décadas de 1960 a 1970 (MORENO, 2007).
} 
indivíduos e grupos deslocados de outras regiões do país e do próprio Mato Grosso, e foi deles que saíram a maioria dos assentados que integraram os assentamentos situados no meio norte do estado. Não por acaso, é comum uso de categorias associadas aos seus locais de origem - "gaúchos", "cuiabanos" - ou o local de acampamento - "turma de Nobres", "turma da Pedra Preta", "turma da baixada cuiabana" - para classificar os assentados (DESCONSI, 2015), os quais, mais do que designar a própria origem, carregam determinados atributos sociais que os distinguem (HEREDIA; PALMEIRA, 2009). Entre os assentados que exploram a produção de soja predominam aqueles do sul do Brasil ${ }^{7}$ que se envolveram em processos de luta pela terra em Mato Grosso.

Ao circular pelas terras da região, é difícil distinguir na paisagem as terras das grandes explorações agrícolas - "as fazendas" - e as terras ocupadas por assentamentos rurais. Quem imagina assentamentos, com uma paisagem formada por casas rodeadas por árvores, criação de pequenos animais, existência de muita movimentação de pessoas ou mesmo uma maior diversidade nos cultivos dispostos nas terras, surpreende-se ao observar que tal cenário se apresenta como marginal na maioria dos 10 assentamentos que conhecemos localizados nos municípios de Sorriso, Nova Ubiratã, Ipiranga do Norte, Itanhangá e Tabaporã. Nos sete assentamentos localizados no município de Ipiranga do Norte, que totalizam aproximadamente 54 mil hectares, a soja ocupa aproximadamente 49 mil hectares, ou seja, mais de $85 \%$ do total segundo os dados da própria Secretaria Municipal da Agricultura. O mesmo se repete em assentamentos do município de Sorriso (Santa Rosa II), Nova Ubiratã (Piratininga) e Itanhangá (Itanhangá), os quais a soja alcança entre 80 a $90 \%$ de todas as terras, segundo os dados obtidos em campo.

Sem um exame aprofundado, rapidamente, o pesquisador é levado a pressupor que a presença de soja em assentamentos rurais é produto da concentração fundiária (estabelecida por meio da posse ou pelo uso da terra), na qual os fazendeiros, empresários ou produtores da região estariam se apropriando das terras dos assentados. Sem desconsiderar a existência de tais situações, verificase a existência de assentados envolvidos com a produção de soja, cuja soma das diversas áreas variavam entre 70 a 300 hectares em uma região onde a média dos estabelecimentos é de 1.150 hectares, conforme dados do Instituto Brasileiro de Geografia e Estatística (IBGE), e onde representantes das instituições patronais afirmam que são necessários pelo menos 1.000 hectares para a "viabilidade econômica" desse tipo de produção ${ }^{8}$. Por ser um tipo de produto característico de grandes explorações agrícolas, como poderíamos compreendê-lo nas áreas dos assentamentos? As pistas que seguimos para examinar tais especificidades vieram de relatos muito comuns entre os assentados: "aqui a gente planta em família”, que nos indicaram a relevância de mapear e compreender a construção de arranjos no entorno desse tipo de lavoura comercial ${ }^{9}$.

\footnotetext{
${ }^{7}$ Outros estudos que se dedicaram ao estudo dos produtores de soja em Mato Grosso também observaram a predominância daqueles oriundos do sul do Brasil, geralmente designados como "gaúchos" (FERNANDEZ, 2007; DESCONSI, 2011; ALMEIDA, 2013).

${ }^{8}$ Em diversas entrevistas com produtores de Sorriso, eles indicavam que a produção de soja só era viável economicamente em unidades com tamanho mínimo de 800 a 1.000 hectares. Esse mesmo parâmetro pode ser encontrado na literatura agronômica que fala em unidades mínimas de 1.000 hectares para essa região do Mato Grosso. No entanto, na área de pesquisa, encontram-se diversos casos de produtores que plantavam soja em áreas inferiores a 350 hectares, em alguns casos específicos, até 70 hectares.

${ }^{9}$ Há uma vasta literatura antropológica sobre o campesinato que dedicou atenção à relação entre família e a exploração agrícola. O primeiro aspecto destacado pela literatura é a consideração que tais atividades produtivas ou econômicas estão subordinadas às relações sociais, especialmente de parentesco, e não o inverso (THOMAS; ZNANIECKI, 1918; ARENSBERG; KIMBALL, 1968; BOURDIEU, 1977; entre outros). Nessa direção, parte da literatura sobre campesinato identificou a interdependência entre família, trabalho e a terra (HEREDIA, 1979; GARCIA Jr, 1983; entre outros).
} 
Fazer menção à "família", para a maioria dos assentados, significa tratar dos vínculos estabelecidos entre diversos indivíduos a partir de relações de aliança - formado a partir dos casamentos - e filiação - menção aos pais e filhos (as) e/ou irmãos (ãs). Quando se tratam de casais jovens, geralmente, falar de família significa falar da família "do lado dele" ou "do lado dela", por vezes, agregando os cunhados (as). Já para os casais "mais velhos", falar de família é fazer menção aos filhos (as) e, eventualmente, netos (as) e dar menor peso aos irmãos e irmãs. Raramente, o significado de família aparece associado somente a um casal e seus filhos, quando ainda jovens, embora haja menção à "casa", que, mais que a própria ideia de propriedade, demarca a existência de um novo grupo doméstico ${ }^{10}$. O casamento implica em construir uma residência, nem sempre associada a uma parcela de terra individual, pois isso depende das condições objetivas para tal.

Para fins da análise proposta neste artigo, faz-se uso dessa noção nativa de família que implica examiná-la como um agrupamento social concreto e dinâmico, que se aproxima muito da noção de família exposta no clássico estudo de Thomas e Znaniecki, (1918). Mas, ao citar tal semelhança, é fundamental observar outra contribuição dos autores, inédita para a época, que se refere à importância das interações entre membros de uma família ou, dito de outra forma, a dimensão do cotidiano, perspectiva que foi aprimorada nas décadas recentes por diversos autores/as. Entre eles/as está Gessat-Anstett (2001, p. 124), que utiliza a noção analítica de "rede" entendendo-a como composta de "relações entre indivíduos e grupos num suporte específico (econômico, parental, afetivo)”. Isso implica em formas específicas de ativação dos parentes e de (re) produção de mecanismos de legitimação do que se entende por família nesse processo. Para ela, a "rede" trata-se de um agrupamento de parentesco que ganha forma não só por meio dos laços de filiação e aliança, mas também por meio das "trocas" de bens e de serviços. Entende-se assim que a autora estabeleceu uma dimensão observável, que permite ao pesquisador mapear a rede de refletir sobre a própria noção de família em contextos específicos.

A seguir, descreve-se o caso da família Denatti ${ }^{11}$ de modo a demonstrar como se constitui uma "rede familiar" a partir da necessidade de mobilizar pessoas e recursos para "dar o suporte" da produção de soja em dois assentamentos do meio norte mato-grossense.

\footnotetext{
${ }^{10}$ Fortes (1971), para fins analíticos, estabeleceu a distinção entre a noção de grupo doméstico (e seus ciclos) entendendo este como a unidade básica de reprodução social. Já a noção de família seria composta por um núcleo de duas gerações interligadas pelo princípio de filiação.

${ }^{11}$ Neste artigo utilizam-se nomes e sobrenomes fictícios para os participantes da pesquisa com o objetivo de preservar a identidade dos mesmos.
} 


\section{A família mobilizada para plantar}

Os membros da família Denatti se dividiam entre as "terras novas"12 do assentamento Mercedes e as "terras velhas" de Ipiranga do Norte (e a cidade do mesmo nome). As múltiplas articulações em forma de rede envolviam, de diferentes maneiras, mais de 30 pessoas, predominantemente familiares, como também se estendiam a alguns vizinhos e conhecidos e abrangiam o uso mais de dez lotes de terra.

Arno Denatti costumava se referir ao filho, dois genros e duas filhas, uma nora, seu irmão, cunhada e sobrinho como a "família" articulada nas lavouras de soja e arroz implantadas no assentamento Mercedes. Nesse ponto, é preciso observar que a família entra em cena ainda antes da chegada aos assentamentos, seja no ingresso conjunto de vários membros - pais e filhos (jovens), irmãos e/ou cunhados - no processo de luta pela terra em acampamentos e ocupações. Da mesma forma, outros tantos casos nos quais, após o ingresso de um membro da família nas terras do assentamento, abre-se caminho para o deslocamento de outros, tal como demonstrado em Desconsi (2011, p. 197-200). Dessa maneira, é comum encontrarmos nos assentamentos vários membros de uma família, que buscaram, por essas vias, estarem mais próximos um dos outros e, dessa forma, dispor de pessoas "com quem se pode contar", e muitos deles vão ser mobilizados para constituir os recursos necessários para implantar as lavouras de soja no assentamento.

Na Figura 01, apresenta-se um extrato da genealogia com todos os indivíduos mapeados, distinguindo os membros que participavam ou não da exploração agrícola, segundo a percepção do assentado.

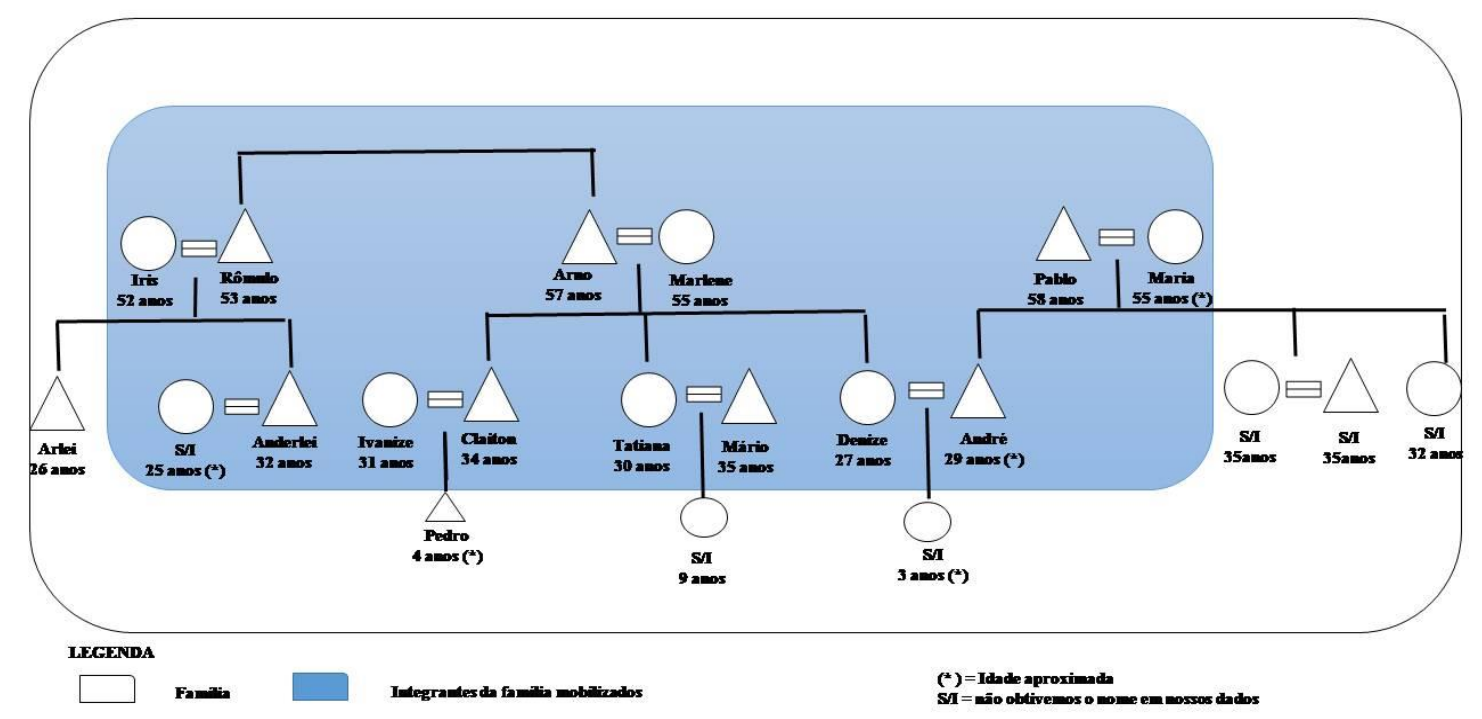

Fig. 1: Extrato da genealogia com identificação da rede de suporte no interior da rede familiar e respectivos integrantes. Fonte: dados obtidos pelo autor

\footnotetext{
12 "Terras novas" eram áreas que estavam em processo de desmatamento e implantação dos primeiros anos de cultivos agrícolas comerciais de arroz e soja. Já o termo "terras velhas" se referia às áreas ocupadas por lavouras de soja e milho há pelo menos 10 anos. O contexto estudado apresentava assim determinados assentamentos considerados de "terras novas" - particularmente, o assentamento Mercedes pertencente ao município de Tabaporã/MT - e assentamentos situados em "terras velhas" - no caso, aqueles situados em Ipiranga do Norte/MT. De modo geral, o caso a ser descrito nas páginas seguintes atravessava esses dois espaços, o que implicava em dinâmicas próprias para atender a práticas de uso da terra e ao calendário anual distintos em cada uma delas.
} 
A partir da Figura 01, é possível distinguir três faixas etárias entre os integrantes da rede familiar. A primeira constituída pelos "mais velhos", com idade variando entre 50 a 65 anos. Seus filhos/as casados/as, "os mais novos", formavam o segundo grupo etário com idades entre 24 a 35, cujos filhos/as não superavam os 10 anos de idade. Estes últimos, constituindo o terceiro grupo etário. As redes familiares que sustentavam as lavouras sobre as "terras novas", com frequência, envolviam indivíduos da geração "mais velha" e da geração "mais nova" e eram estabelecidas, geralmente, a partir do pai e um filho.

Nesse caso, vê-se a mobilização de sete grupos domésticos, todos integrantes da rede familiar. Isoladamente, cada um deles, a priori, contava com recursos insuficientes para desencadear a exploração agrícola a partir da lavoura de soja. A amplitude da rede coincidiu com uma dinâmica mais ampla de crescimento das terras ocupadas pela soja no assentamento Mercedes, intensificada a partir de 2008, quando uma firma regional compradora de soja se instalou na área. Foi a partir desse momento que foram fortalecidos múltiplos acordos entre familiares e não familiares, visando acompanhar o ritmo de transformação das terras e criar as condições para plantar soja.

$\mathrm{Na}$ Figura 1, observa-se que todos/as os/as filho/as e genros de Arno estavam envolvidos, em diferentes níveis, na exploração agrícola, ainda que, como demonstraremos adiante, isso nem sempre foi assim. O mesmo não se pode dizer de Rômulo e Pablo, que possuíam cada qual somente um filho (casado) integrado à exploração agrícola. Não estavam incluídos, segundo seus relatos, o segundo filho de Rômulo e as filhas (e genros) de Pablo. Entretanto, isso não significa que estes não pudessem ser mobilizados para a exploração agrícola em algum momento. Em 2013, por exemplo, o filho de Rômulo que residia na Espanha deslocou-se para o assentamento atendendo ao pedido dos pais. As informações coletadas sugerem que o "chamamento" do filho objetivou, de um lado, tê-lo mais próximo dos demais membros da família e, de outro lado, integrálo à exploração agrícola, observando as possibilidades de ampliação das terras em uso no assentamento. Contudo, a experiência durou pouco, e ele retornou para o exterior. O exemplo do "chamamento" serve para considerar que a necessidade de pessoas para o trabalho (e para mobilizar outros recursos), vinculadas às possibilidades de ampliação das terras em uso, poderia "abrir espaço" para outros membros "da família" serem mobilizados na rede, mesmo que estivessem, oportunamente, residindo em locais distantes ${ }^{13}$.

Também foi a partir do boom da soja no assentamento, por exemplo, que os dois genros de Arno passaram a fazer parte da rede mobilizada no entorno da lavoura. Em 2011, Mário ( $1^{\circ}$ genro) acordou com o sogro Arno que cederia "seu nome" 14 para fins de registro do lote no assentamento Mercedes junto ao Incra. Embora o registro proporcionasse direito à posse do lote, entre eles, isso não era compreendido nesses termos, visto que nem Mário nem os demais membros da família o reconheciam como detentor da posse. Contudo, esse dispositivo foi o primeiro passo para integrá-lo na exploração agrícola, contribuindo com o sogro e o cunhado (Claiton). Mário trabalhava durante todos os dias da semana na sua revenda agropecuária em Ipiranga do Norte. Mesmo assim, de forma frequente, fazia o deslocamento de mais de $140 \mathrm{~km}$ até o assentamento Mercedes, levando

\footnotetext{
${ }^{13}$ Para saber mais sobre o "chamamento" de familiares, antigos vizinhos e conhecidos como uma das dimensões da migração para o Mato Grosso, ver Desconsi (2011, p. 197-200).

${ }_{14}$ Nesse caso em particular, trata-se do "nome" não como pessoal moral associado ao "nome de família", por exemplo, mas como um "objeto" inalienável que pertence ao indivíduo ou rede familiar, que era "emprestado", "trocado" e tinha usos variados para fins de registros oficiais.
} 
suprimentos (alimentos, peças para as máquinas etc.), apoiando o sogro nas tarefas associadas à abertura de áreas ${ }^{15}$. Também possuía participação em algumas transações comerciais que, embora fossem registradas em "seu nome", estavam sobre o controle do sogro e o cunhado.

Mário passou a participar da exploração agrícola depois de cinco anos do casamento, quando houve a necessidade de mais recursos para dar conta da abertura e implantação de lavouras nas "terras novas". Entretanto, essa participação deve ser entendida em relação a manifestações de apoios anteriores, não associados às lavouras, mas que são relevantes para explicar a obrigação para com o sogro e o cunhado. Falamos, de modo particular, sobre a articulação que viabilizou o estudo de Tatiana (esposa de Mário):

Ela [filha] estava em Cuiabá, na faculdade. (...) a gente conseguiu, porque eu ajudei, o genro também, foi muita dificuldade, porque eles têm uma filha de nove anos praticamente. Ela ficou quatro a cinco anos só com nós, com a minha esposa e ela vinha uma vez ou duas por mês pra cá. Mas agora esse genro está dando suporte lá na Mercedes, porque estava precisando lá que está no forte (Arno, assentado de Ipiranga do Norte, 21/10/2013).

Para Mário, a obrigação de atender ao chamado do sogro não se devia somente ao laço instaurado pelo casamento com a filha, mas ao apoio concreto no cuidado com a sua filha pequena durante a ausência da esposa. Essa se constituía como uma espécie de dívida, que estabelecia o compromisso de retribuição, o que só tomou forma a partir de sua inserção na exploração agrícola. Nas "terras novas", em regra, os investimentos eram maiores que as colheitas obtidas, reduzindo as possíveis sobras. De qualquer modo, Mário não integraria a eventual divisão das mesmas, o que nos leva a supor que sua contribuição na exploração agrícola estava subordinada ao sogro e ao cunhado, sendo uma forma de retribuição de um "suporte" anterior dado pela rede familiar.

Na mobilização da família para plantar, André ( $2^{\circ}$ genro), também entrou em cena. Este, diferente de Mário, era um assentado que, desde 2002, estava envolvido na exploração agrícola junto ao pai e vizinhos no assentamento Mercedes. Na busca por ampliar suas terras, em 2012, André e seu pai (Pablo) adquiriram um lote de 55 hectares de "terra bruta" 16 , para ser agregado aos outros dois que já possuíam. No entanto, ao investirem na compra do lote, faltou-lhes recursos para, posteriormente, "abrir a terra" e, por isso, ele "deu a terra" ${ }^{17}$ para que o sogro e o cunhado explorassem por um período de oito anos.

A cessão da terra para o sogro exprimia um desejo de manter o uso da terra "na família". Entretanto, somente "ser da família" (sogro, cunhado, por exemplo) não seria suficiente para confiar a terra se não creditasse a eles a capacidade de implantar lavouras. Por isso, a opção pelo sogro também observou as suas experiências recentes na exploração da terra ${ }^{18}$, suas condições materiais

\footnotetext{
15 “Abertura de áreas” significa um conjunto de tarefas relacionadas à eliminação da vegetação nativa do Cerrado, sobretudo, o desmatamento, a sistematização da área e a correção química do solo.

${ }^{16}$ Área de terra com vegetação natural típica do Cerrado.

${ }^{17}$ É importante esclarecer que quando a terra é mencionada como objeto de troca, por vezes, associado ao termo "dar", isso talvez se aproxime mais ao "emprestar", ou ao "dar para uso", não entregar a posse, visto que o termo carrega o sentido de uma doação, parte da troca de algo não alienável, de uma coisa que, mesmo dada, não está separada do seu doador. "Dar" ou "passar a terra" para que outro faça uso como se fosse sua e, assim, possa, em última instância, não só obter boas colheitas dessa terra, mas contribuir para melhorá-la ao longo do tempo (BOURDIEU, 1977; GODELIER, 2001; DUFY; WEBER F., 2007). Para essa atribuição estabelecer uma relação de troca para uso, sugere também que essa troca seja feita com alguém com a qual o detentor da área de terra acredite que tenha condições de exercer essa tarefa.

${ }^{18}$ Diversos trabalhos identificaram em comunidades camponesas normas do grupo que visavam evitar que a terra caísse em mãos de estranhos. Para exemplificar, nos estudos de Bourdieu na Argélia, ele assim se refere: "evitar que a terra caia na mão de uma família estrangeira é um dever. A terra deve estar em mão daqueles que trabalham nela” (BOURDIEU, 1977, p. 35, tradução nossa).
} 
(tratores e implementos, dinheiro) e outros "capitais"19 (relacionamento com as firmas e os bancos) a serem mobilizados para o empreendimento da lavoura. Sem dispor dessas condições, essa terra poderia, como efetivamente ocorria em muitos casos, ser confiada a não familiares que demonstrassem tais condições.

Isso se confirma quando examinamos a situação de dois vizinhos que foram mobilizados nessa rede, particularmente por Pablo e André. Os vizinhos pai e filho - possuíam cada qual um lote de terra e sua força de trabalho, ou seja, recursos insuficientes para instaurar o processo conversão das terras em lavouras; com efeito, procuraram Pablo e André, que possuíam o conjunto das condições necessárias para fazê-lo. Na parceria, os vizinhos cederam a terra para os mesmos "abrir e plantar" por um período de oito anos. Estes, por sua vez, seriam encarregados de arcar com todas as despesas referentes à abertura (combustível, calcário, pagamento de empreitada na catação de raízes, entre outros), enquanto que os vizinhos passariam a trabalhar para os mesmos.

Observa-se que Pablo e André passaram a fazer uso da terra dos vizinhos, e não do próprio lote - "da família” - o qual havia sido repassado para o sogro. O que está em jogo aqui é a possibilidade de incorporar a terra dos vizinhos na composição de terras em uso pela rede familiar de forma duradoura e, de forma complementar, contar o trabalho dele para tocar a exploração agrícola. Se o Pablo e o André optassem em fazer uso de seus dois lotes, não teriam condições financeiras para tocar um terceiro lote, e isso exigiria que André estivesse o tempo todo nas tarefas agrícolas das "terras novas". Nesse sentido, a estratégia de ceder o lote para o sogro e, paralelamente, fazer a "parceria" com o vizinho permitiu que André e a esposa se mudassem para a cidade de Ipiranga do Norte em 2012, onde ambos começaram a trabalhar em firmas, de onde tiravam seu sustento e economizavam algum valor para investir nas "terras novas". Já a sua articulação com o sogro e o cunhado garantia que o trabalho de "melhorar a terra" fosse feito para alguém "da família", atribuição que tinha como retribuição a possibilidade de utilizar a terra também por oito anos.

Dentre os vários indivíduos acionados estavam irmãos e sobrinhos de Arno com os quais costumavam "trocar serviço" para executar as tarefas do calendário agrícola. Nas proximidades de suas terras, estavam seu irmão Rômulo, 52 anos, casado com Iris, 53 anos, e mais Anderlei ( $1^{\circ}$ filho), 32 anos, casado e com um filho pequeno. Pai e filho possuíam dois lotes, adquiridos em 2004, quando migraram diretamente de Santa Helena/PR. Além de seus lotes, eles trabalhavam outros dois lotes de "antigos vizinhos" - também pai e filho - que não residiam na região. Nesses lotes, Rômulo e Anderlei se encarregavam da abertura das áreas, do cultivo do arroz e da soja e do manejo do gado. $\mathrm{O}$ manejo dos animais lhes dava direito à parte dos bezerros nascidos a cada ano, os quais eram criados nas pastagens implantadas nas terras dos "antigos vizinhos". Nas lavouras de arroz e soja, de maneira um pouco diferente, Rômulo e Anderlei entravam com o trabalho físico e mecanizado (com dois tratores e implementos). Os "antigos vizinhos" disponibilizavam dinheiro para as despesas com combustível, adubos, sementes e, por fim, no caso específico da soja, encarregavam-se da colheita e transporte com suas máquinas e caminhões. Estes, embora residissem no Paraná, todos os anos, na época da colheita de soja, eles faziam jornadas de mais de 30 dias "prestando serviço" de colheita com suas máquinas em terras mato-grossenses. Em suma, as articulações de Rômulo e o filho com os "antigos vizinhos" permitiam aos primeiros disporem de mais terras para realizar a exploração agrícola e para os segundos as condições para que pudessem investir

${ }^{19}$ Conforme noção de "capital” de Bourdieu (2009). 
nas "terras novas" e realizar tarefas agrícolas diretamente ao longo do calendário anual.

A Figura 2 a seguir representa as múltiplas articulações que dão forma a uma rede familiar para dar conta do uso da terra. Seguindo a sequência de nossa descrição nesta subseção, cada cor representa um agente (total de 9 cores). Cada um deles se conectava a outros por meio de "trocas", disponibilizando recursos diversos, visando viabilizar a lavoura em determinadas áreas.

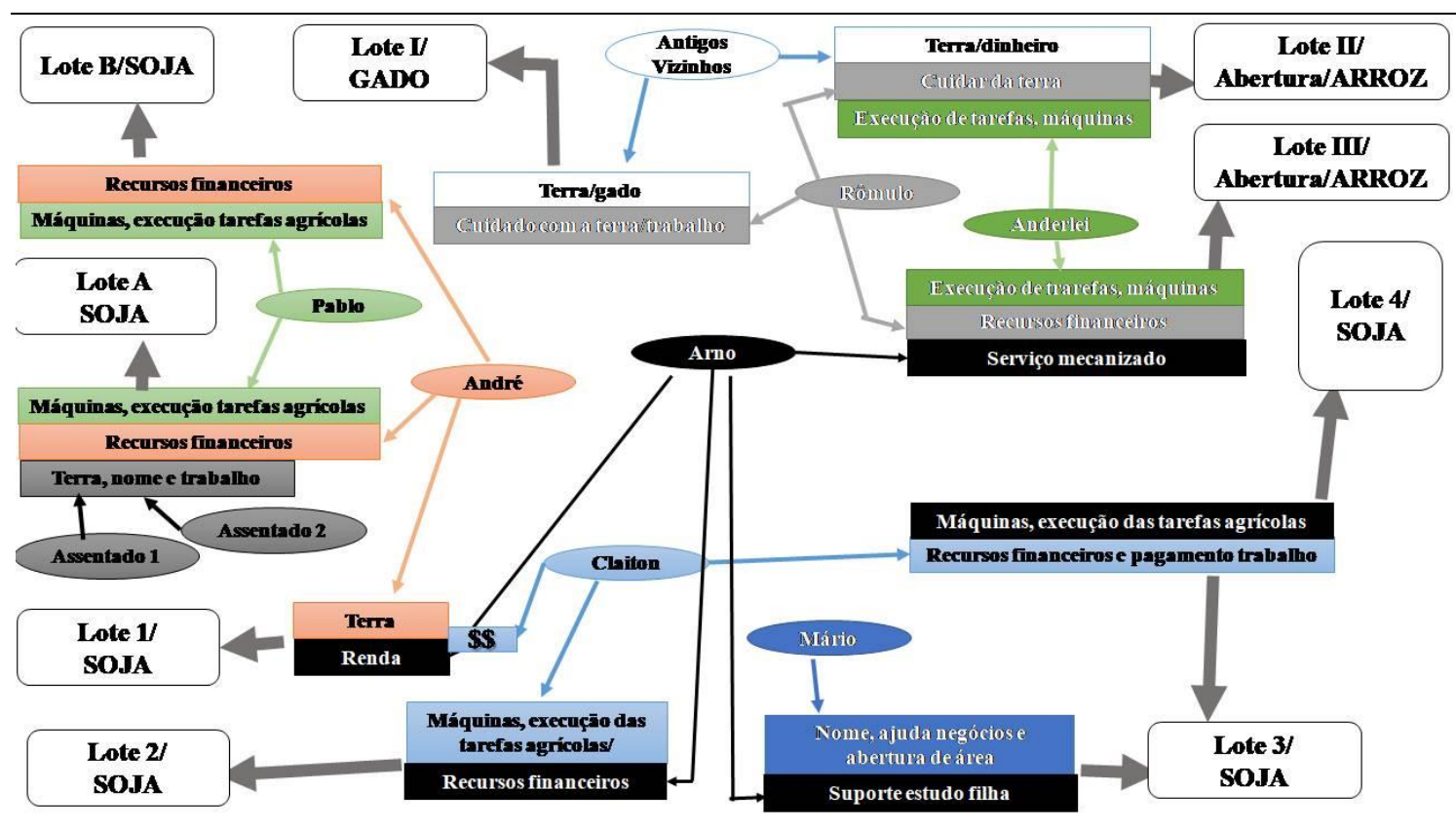

Fig. 2: Rede mobilizada para tocar lavouras de soja. Fonte: elaborado pelo autor

Redes familiares mobilizadas para tocar lavouras, com arranjos similares a este, são recorrentes nos assentamentos do meio norte do Mato Grosso e devem ser consideradas como uma das vias para compreender a participação dos assentados na produção de soja.

Apresentada a composição dessa rede e dos diversos acordos e trocas que produzem as conexões entre os integrantes, na seção a seguir, procura-se apresentar algumas notas para refletir sobre a relação entre família e exploração agrícola nesse contexto em particular.

\section{A rede familiar e o "suporte" à lavoura de soja}

Entre os assentados envolvidos com as lavouras de soja, raramente encontramos aqueles que o fazem somente dentro dos limites de seu lote individual ${ }^{20}$ e tão menos envolvendo, nessa exploração, somente os membros de um mesmo grupo doméstico. Muito mais do que dispor de uma área de terra para plantar e capacidade física para o trabalho, é preciso dispor de máquinas para realizar as tarefas, acessar recursos financeiros - geralmente acionados em bancos ou firmas - possuir capacidade de lidar com a "economia de mercado" - que envolve tarefas de comprar, vender, negociar, acompanhar a flutuação dos preços etc.

${ }^{20}$ Os lotes individuais nos assentamentos rurais estudados possuem área que varia entre 70 a 90 hectares. 
Para dispor desse conjunto de recursos, os assentados mobilizavam membros da família, vizinhos e conhecidos para lidar com a lavoura. Um assentado poderia mobilizar uma gama muito variada de relações, embora houvesse preferência em constituir redes que envolvam membros da família.

Todavia, nem todos os assentados possuíam membros da família nos assentamentos ou proximidades para mobilizar. Nesses casos, havia uma maior tendência para a construção de acordos com vizinhos ou mesmo fazendeiros do entorno dos assentamentos. Em outras situações, os assentados possuíam "família grande" no assentamento, mas não possuíam recursos para além da capacidade física de trabalho e do lote de terra, como máquinas, dinheiro e relacionamento com as firmas. Ainda que o maior número de membros adultos significasse maior capacidade de trabalho, era necessário converter este em outras modalidades de recursos, condição nem sempre possível. Esse aspecto é relevante para entender tanto quais indivíduos são chamados para integrar o "suporte" associado às lavouras de soja como quais assentados participam e quais não ou, ainda, como se dá essa participação do cultivo do produto predominante nas terras do meio norte mato-grossense. Dá-se preferência a quem é "da família”, mas é preciso que alguns dentre eles possuam determinados recursos materiais para materializar a implantação das lavouras.

Se entre os assentados era comum fazer referência às lavouras como sendo "tudo em família" ${ }^{21}$, isso não significava que essas lavouras pudessem, necessariamente, ser consideradas como empreendimentos coletivos ou individuais. Num primeiro momento, fica evidente que a menção à "família" entre os assentados, geralmente, dava destaque a determinados membros da "rede familiar" que estavam, de alguma maneira, articulados no entorno da exploração agrícola e a alguns dentre eles que detinham maior controle do processo produtivo, em detrimento de outros que, embora fossem "da família", nem sempre eram lembrados. Num segundo momento, é preciso considerar as diferenças entre os indivíduos ou grupos domésticos, o que pode ser observado nas especificidades em que cada acordo foi construído entre os integrantes para compor a rede, tal como ilustrado no caso da seção anterior.

Sobre esse aspecto, aliás, a descrição também aponta entre os integrantes articulados na rede alguns indivíduos que dispunham de maior controle sobre as pessoas e as práticas associadas à exploração agrícola. $\mathrm{Na}$ rede em análise, o controle sobre os diversos integrantes gravitava em torno de alguns "núcleos" compostos por um pai ("mais velho") e por um filho ("mais novo") sendo: Arno e Claiton; Rômulo e Anderlei; Pablo e André. A partir desses três pares é que se formaram as diversas articulações apresentadas da Figura 02. Eram eles que eram classificados como "os que plantavam" em relação aos demais integrantes da rede familiar (irmãos, irmãs, cunhados, sogros) ou ainda "parceiros" vizinhos "que davam suporte". Quanto aos vizinhos, observa-se que, em alguns casos, eles também estavam mobilizados a partir de um pai e de um filho, contudo, quando postos em relação aos três núcleos mencionados, assumiam condição inferior, devido ao menor controle de recursos que possuíam, assim como a tomada de decisão sobre a condução da lavoura.

\footnotetext{
${ }^{21}$ Mesmo que o trabalho em conjunto como uma característica constitutiva do que se entende por família camponesa (ARENSBERG; KIMBALL, 1968), isso não pressupõe que seja algo homogêneo ou realizado entre iguais. O estudo de Heredia (1979) que analisou a organização interna das "famílias" de pequenos produtores em outro universo social colocou em evidência várias distinções a partir de sexo, idade, número de filhos e fase do ciclo de vida dos membros, que contribuíam para manter e/ou estabelecer hierarquias entre os membros.
} 
A rede apresentada na seção anterior, evidentemente, foi composta em um momento que as lavouras de soja ampliavam seu espaço no assentamento Mercedes. Isso sugere seu caráter flexível, podendo este ser apenas uma situação eventual. Entretanto, eram exatamente por meio dessa mobilização entre familiares e vizinhos que alguns assentados ampliavam as terras em uso - recurso essencial nessa modalidade de exploração agrícola - e buscavam estabelecer o controle sobre as lavouras para além de suas posses individuais, sem efetivamente utilizar a estratégia de adquirir novas terras. Nesse sentido, ainda que com modificações, seus integrantes objetivavam manter a mobilização dos integrantes entre si, de modo a torná-la duradoura, pois esse era o caminho para manter uma dada composição de terras em uso para implantar lavouras para além de seu lote individual. O sucesso ou não dessa pretensão dependia da habilidade de produzir obrigações (ou mesmo dívidas) atualizadas no cotidiano, por meio de trocas de bens e serviços associadas à exploração agrícola, primordialmente.

Se observarmos na Figura 02, vemos que cada grupo doméstico parece estar participando de forma direta da exploração agrícola em pelo menos três lotes de terra, o que significa uma composição de área entre 150 a 300 hectares de lavouras de soja, nesse contexto. Essa quantidade, segundo os assentados, constituía como um parâmetro próximo ao ideal, conforme relato de um assentado em referência à mobilização da família:

\begin{abstract}
Para plantar, é preciso ter mais de um lote e ter a família grande ou vizinhos bons. Porque se vai ter uma máquina para colher, uma para plantar e outra para passar veneno, isso envolve quantos mil para pagar? Precisa quanto? Com esse mesmo maquinário, você faz 5 a 6 lotes, até 30o, 400 hectares. Ou, no mínimo, planta do vizinho e de mais alguém. No caso do tio, é ele que planta na minha terra. Planta, cuida, passa veneno como se fosse dele (Jackson, assentado, 13/o9/2008).
\end{abstract}

Refletir sobre a constituição de casos como este evoca certo cuidado na análise sobre a concentração de terra, que, na maioria dos estudos, baseia-se em categorias informadas pelo Estado, tais como "lote", "estabelecimento rural", "propriedade", "arrendamento", para dimensionar as unidades territoriais e sociais. Sem desconsiderá-las, parece pertinente tomá-las apenas como indicativos de processos que, necessariamente, devem ser complementadas pelo exame das práticas de uso da terra e dos agentes envolvidos no cultivo de soja. Sobre esse aspecto, o exame aqui apresentado aponta menos para uma delimitação de unidades territoriais a partir da oposição entre individual/coletivo e mais para o mapeamento de composições de áreas em uso para lavouras de soja, que também são composições sociais flexíveis (formadas por redes familiares e afins) atravessadas por uma multiplicidade de acordos e trocas que distinguem seus integrantes um dos outros. Estas só podem ser captadas a partir das formas de classificar dos próprios agentes envolvidos. Não se trata, por exemplo, de classificar a priori que a lavoura $\mathrm{X}$ pertence ao assentado $\mathrm{A}$ ou $\mathrm{B}$, tão menos, em situação oposta, considerar que a lavoura é um empreendimento coletivo, no sentido de um todo homogêneo. Nesse sentido, a noção de rede, aqui inspirada em Gessat-Anstett (2001), parece contribuir para ao menos relativizar as classificações e evidenciar a complexidade existente na relação entre família e exploração agrícola, pelo menos no contexto dos assentamentos observados.

Por fim, a análise aqui apresentada procurou, refletir sobre as imbricações entre práticas econômicas e as relações sociais, particularmente das redes de parentesco, dos agentes envolvidos. Nesse sentido, acreditamos ter conseguido demonstrar a pertinência da relação entre família e exploração agrícola para 
compreender a participação dos assentados na produção de soja e a própria predominância espacial das lavouras de soja nos assentamentos pesquisados. Cabe ressaltar que os dados etnográficos também apontam a existência de redes mobilizadas no entorno de lavouras de soja não restritas ao círculo do parentesco, mas construídas entre vizinhos e/ou envolvendo produtores e fazendeiros do entorno do assentamento, as quais não foram examinadas nos limites desse artigo e, por isso, se tornarão objeto de futuros trabalhos.

Recebido em 15 de dezembro de 2017.

Aprovado em 14 de agosto de 2018.

\section{Referências}

ALMEIDA, L. Gaúchos, festas e negócios: o agronegócio da soja no meio norte do Mato Grosso. Tese de doutorado, Programa de Pós-graduação de Sociologia e Antropologia/UFRJ, 2013.

ARENSBERG, C; KIMBALL, S. Family and community in Ireland. Harvard University Press, 1968.

BOURDIEU, Pierre. Argélie 6o: structures économiques et structures temporalles. Paris, Les Éditions de Minuit, 1977.

BOURDIEU, P. O senso prático. Petrópolis/RJ, Ed. Vozes, 2009.

DESCONSI, C. A marcha dos pequenos proprietários rurais: trajetórias de migrantes do sul do Brasil no Mato Grosso. Rio de Janeiro, E-papers, Coleção Sociedade e Economia do Agronegócio vol. I, 2011.

DESCONSI, Cristiano. Famílias do sul do Brasil na luta pela terra em Mato Grosso. Anais do XVII Congresso Brasileiro de Sociologia, Porto Alegre/RS, 2015.

DUFY, C; WEBER, F. L'ethnographie economique, Paris La Découverte, 2007.

FERNANDEZ, A. J. C. Do Cerrado à Amazônia: das estruturas sociais da economia da soja em Mato Grosso, Tese de doutorado, Programa de Pósgraduação em Desenvolvimento Rural/UFRGS, 2007.

FORTES, M. Introduction. In: GOODY, Jack. The Developmental Cycle in Domestic Groups. Cambridge: Cambridge University Press, 1971, p. 1-14.

GESSAT-ANSTETT, É. "Du collectif au communautaire. À propos des réseaux familiaux dans la Russie post-soviétique". L'Homme. EHESS. $\mathrm{n}^{0} 157$ janvier/mars, 2001, p.115-136.

GODELIER, M. O legado de Mauss. In: O enigma do dom. Rio de Janeiro, Civilização Brasileira, 2001, p. 19-161.

HEREDIA, Beatriz, PALMEIRA, Moacir; LEITE, Sérgio Pereira. Sociedade e Economia do "Agronegócio" no Brasil. Revista Brasileira de Ciências Sociais, vol. 25, $\mathrm{n}^{\circ} 74$, 2010, p. 159-196. 
HEREDIA, B. A. A morada da vida: trabalho familiar e pequenos produtores do Nordeste do Brasil. Rio de Janeiro, Paz e Terra, 1979.

HEREDIA, B; PALMEIRA, M. Migrações em áreas de agronegócio. Travessia Revista do Migrante. São Paulo, no 65, set-dez, 2009, p. 71-88.

MORENO, G. Terra e poder em Mato Grosso: política e mecanismos de burla 1892-1992. Cuiabá. EduUFMT, Entrelinhas, 2007.

THOMAS, W. I.; ZNANIECKI, F. The Polish Peasant in Europe and America. Boston, Gohan Press, vol.1, 1918.

WESZ Jr., W. O Mercado da soja e as relações de troca entre produtores rurais e empresas no sudoeste de Mato Grosso. Rio de Janeiro, Tese de doutorado, Programa de Pós-graduação em Ciências Sociais em Desenvolvimento, Agricultura e Sociedade/UFRRJ, 2014. 